\section{Kinetic Model of Gas Bubble Dissolution in Groundwater and Its Implications for the Dissolved Gas Composition}

\author{
J. HOLOCHER, ${ }^{\dagger}$ F. PEETERS, ${ }^{*},{ }^{+}$ \\ W. AESCHBACH-HERTIG, \\ W. KINZELBACH, $\neq A N D R$. KIPFER ${ }^{\dagger, \S}$ \\ Environmental Isotopes Group, Department of Water \\ Resources and Drinking Water, Swiss Federal Institute of \\ Environmental Science and Technology (EAWAG), $\mathrm{CH}-8600$ \\ Dübendorf, Switzerland, Institute of Hydromechanics and \\ Water Resources Management, ETH Hönggerberg, CH-8093 \\ Zürich, Switzerland, and I sotope Geology, Department of \\ Earth Sciences, Swiss Federal Institute of Technology (ETH), \\ $\mathrm{CH}-8092$ Zürich, Switzerland
}

Bubble-mediated mass transfer is of major importance for the gas exchange between soil air and groundwater. The presence of entrapped air bubbles in the upper, quasisaturated aquifer zone can crucially affect the interpretation of atmospheric trace gas concentrations in groundwater and associated fluids as well as intrinsic and enhanced bioremediation procedures that rely on the actual dissolved gas content of gases such as oxygen or nitrogen. To describe the bubble-mediated gas exchange in detail, a kinetic multi-species model for dissolved gas transport in a porous medium including inter-phase mass transfer with entrapped gas bubbles was developed. It takes into account changes in the entrapped gas bubble sizes resulting from the mass exchange and therefore allows the quantification of mass transfer between bubbles of any gas composition and flowing or stagnating water in a substrate column. Considering the dissolution of entrapped air bubbles, the resulting concentrations of dissolved atmospheric gases signific antly exceed their solubility equilibrium concentrations. The temporal evolution of the composition of this excess gas is controlled by the solubility and the molecular diffusivity of the gases considered, by the flow conditions, and by the physical properties of the aquifer such as the ratio of entrapped air to water in the pore space. In the case of noble gases in a through-flow system, solubility differences appear to be more important for the composition of the gas excess than the differences between molecular diffusivities.

\section{Introduction}

The interaction of gas bubbles with a surrounding liquid is an essential part in both natural and technical gas exchange processes. In chemical engineering systems, the dissolution of a discrete gas phase that bubbles through either liquid or

\footnotetext{
* Corresponding author phone: +41-1-823 5531; fax: +41-1-823 5210; e-mail: frank.peeters@eawag.ch.

† Swiss Federal Institute of Environmental Scienceand Technology (EAWAG).

₹Institute of Hydromechanics and Water Resources M anagement.

$\S$ Swiss Federal Institute of Technology (ETH).
}

liquid-solid reactors is an important application. Factors controlling theflux of gasinto theliquid arethe rising velocity of the gas bubbles and the bubble size distribution (1-3). Considering natural environments, the ocean-atmosphere mass transfer is a prominent example of a bubble-mediated gas exchange process. Small air bubbles introduced by breaking waves are dissolved in the near-surface water column, altering the overall water-air gas exchange $(4,5)$. In environmental engineering, the concept of bubblemediated gas transfer has successfully been employed in oxygen bubble plumes to enhance the restoration of deep stratified lakes (6).

In subsurface hydrology, concentrations of dissolved conservative atmospheric gases indicate that the physical processes involved in thegas exchange between atmosphere, entrapped air, and groundwater lead to a supersaturation of atmospheric gases (i.e., that the dissolved gas concentrations are greater than their hypothetical saturation concentrations). The dissolved gas excess has been called excess air (7), and its formation has been attributed to the dissolution of entrapped air bubbles in the uppermost, so-called quasisaturated aquifer zone in therecharge area. Theterm "excess air" is retained, although noble gas data of numerous field studies indicate that the composition of the excess gas does not correspond to atmospheric air (8). Excess air and its fractionation affects theinterpretation of gas concentrations in groundwater [e.g., in noble gas based paleoclimate reconstruction (9-12), in groundwater dating with the ${ }^{3} \mathrm{H}-$ ${ }^{3} \mathrm{He}$ method (12-14), or with $\mathrm{SF}_{6}$ (15)]. Simplified models describing the dissolved gas concentrations in the final state after interaction with entrapped air have been employed to estimateexcessair and its composition $(9,11)$. Whereas these models are appropriate to interpret observed dissolved gas concentrations in terms of few "lumped" parameters, they do not describethe exchange between entrapped air bubbles and groundwater in any detail. In particular, they do not include the kinetics of the gas exchange process and the resulting temporal evolution of dissolved gas concentrations during excess air formation.

Entrapped air not only influences the gas composition but also thetransport dynamics of dissolved gas components in ground water. Retardation of artificially added helium used in tracer experiments in the presence of entrapped air bubbles has been demonstrated (16), complicating the correct interpretation of the tracer data. Injected oxygen used for in-situ bioremediation of groundwater contaminantscan be retarded by entrapped air bubbles as well (17). This is of importancesince the activity of aerobic microorganisms and hence the effectiveness of in-situ bioremediation strongly rely on the availability of injected oxygen. However, even under natural conditions air bubbles that are entrapped during a rise of the groundwater level can serve as oxygen sourcein groundwater, especially in aquifers with a dissolved oxygen deficit.

Except as a sink or source for a single gas component, entrapped air bubbles are usually not included in gas exchange calculations between groundwater and soil air. Correspondingly, theincorporation of entrapped air bubbles into modeling of dissolved gas transport so far has focused on the retardation effect $(17,18)$ or on the oxygen input to anoxic waters (19). Modeling of excess air and its fractionation however requires us to consider changes in the size of entrapped air bubbles and thus to simulate the mass transfer between water and bubbles for all major gas constituents.

We present a kinetic model for dissolved gas transport in a porous medium including inter-phase mass transfer with 
entrapped air bubbles. It considers all major atmospheric gases as well as changes in the entrapped air bubble sizes resulting from the mass exchange and therefore allows detailed studies of the gas composition in the bubbles and dissolved in water. To our knowledge, this is the first model describing the dynamics of the generation of a dissolved gas excess by considering the interaction and dissolution of bubbles of entrapped air with water. The response of different gases to flow and boundary conditions is demonstrated using $\mathrm{N}_{2}$ and $\mathrm{O}_{2}$ as the main constituents of atmospheric air and noble gases as an example for atmospheric trace gases. The latter were chosen because noble gases are only affected by physical processes and data sets from field and column experimentsare available for comparison. Thekinetic model is not intended to replace simplified models that are used to interpret noble gas data $(9,11)$ but to provide a deeper insight into the process of gas exchange between entrapped air bubbles and surrounding water and its effect on the concentration of dissolved gases. The wider aim of our investigation is a better understanding of the mechanisms responsible for the gas exchange between atmosphere and groundwater in general. This will provide a basis to appraise the role of entrapped air bubbles in applications concerned with multi-species volatile organic contaminantsin the upper groundwater zone or in studies employing rare gases as environmental tracers.

\section{Theory}

We consider entrapped air bubbles in the upper, quasisaturated groundwater zone. Such entrapped air bubbles resulting from naturally occurring vertical water movement are spatially fixed since the capillary forces that act to trap the gas phase usually dominate over the buoyancy forces in a natural porous medium (20). The air bubbles are assumed to be spherical and surrounded by water.

If air bubbles are entrapped in a water body that initially was in solubility equilibrium with the atmosphere, gas will be transferred from the bubbles into the water as a result of the pressure that acts on the bubble. This pressure is the sum of the hydrostatic pressure given by the depth of the bubble in the water body and thecapillary pressure resulting from the surface tension of the curved bubble surface. The inter-phase mass flux is proportional to the concentration deficit in the water phase and can be described for gas i by

$$
\mathrm{J}_{\mathrm{i}}=\mathrm{k}_{\mathrm{i}}\left(c_{\mathrm{w}, \mathrm{i}}-\mathrm{c}_{\mathrm{sat}, \mathrm{i}}\right)=\mathrm{k}_{\mathrm{i}}\left(\mathrm{c}_{\mathrm{w}, \mathrm{i}}-\frac{\mathrm{p}_{\mathrm{i}}}{\mathrm{RTK}_{\mathrm{H}, \mathrm{i}}}\right)
$$

where $\mathrm{J}_{\mathrm{i}}$ is the mass flux of the considered gas $\mathrm{i}$ from the aqueous phase to the gas phase $\left(\mathrm{M} \mathrm{L}^{-2} \mathrm{~T}^{-1}\right), \mathrm{k}_{\mathrm{i}}$ is the mass transfer coefficient $\left(\mathrm{L} \mathrm{T}^{-1}\right), \mathrm{C}_{\mathrm{w}, \mathrm{i}}$ is the actual aqueous phase concentration ( $\mathrm{M} \mathrm{L}^{-3}$ ), and $\mathrm{c}_{\text {sat,i }}$ is the equilibrium concentration in the aqueous phase $\left(\mathrm{M} \mathrm{L}^{-3}\right)$. The equilibrium concentration in water is expressed by Henry's law with $\mathrm{K}_{\mathrm{H}, \mathrm{i}}$ as the dimensionless Henry coefficient for the considered gas, $p_{i}$ as the partial pressure of the gas in the air bubble, $R$ as the universal gas constant, and T as the water temperature.

The determination of the correct mass transfer coefficient for bubble-mediated gas transfer can be crucial. Depending on the considered system, several different formulations for k can befound in the literature. An overview of the underlying concepts is given in refs 21 and 22 . Conceptually, the mass transfer between an immobile small entrapped gas bubble and groundwater for volatile gases is limited by a diffusioncontrolled stagnant water film around the bubble. Within the bubble, mixing processes in the gas phase arefast; hence, the gas phase can be described as homogeneous. In our model, we assume the mass transfer coefficient to depend on the water flow condition. Two situations are distin- guished: Bubbles in a stagnant fluid (no-flow regime) and air bubbles that are passed by flowing water (advective regime).

In case of no flow, the mass transfer coefficient $\mathrm{k}$ for a spherical structure with radius $r(L)$ is given by $(21,23)$

$$
\mathrm{k}_{\mathrm{i}}=\frac{\mathrm{D}_{\mathrm{w}, \mathrm{i}}}{\delta_{\mathrm{eff}}}=\mathrm{D}_{\mathrm{w}, \mathrm{i}}\left(\frac{1}{\mathrm{r}}+\frac{1}{\delta}\right)
$$

where $D_{w, i}$ is the gas diffusion coefficient in water $\left(\mathrm{L}^{2} \mathrm{~T}^{-1}\right)$, and $\delta$ is the thickness of the stagnant, diffusively controlled film layer in the liquid around the sphere (L). In no-flow conditions and for small bubble radii, the term $\mathrm{r}^{-1}$ dominates over $\delta^{-1}$. The effective boundary layer thickness $\delta_{\text {eff }}$ is therefore proportional to $r$, and consequently $k_{i} \approx D_{w, i} r^{-1}$.

For advective flow regimes, the boundary layer thickness depends on the flow vel ocity v. In this case, we use (from ref 24)

$$
\mathrm{k}_{\mathrm{i}} \approx \mathrm{D}_{\mathrm{w}, \mathrm{i}}\left(\frac{1}{\mathrm{r}}+\frac{1}{\sqrt{\pi \mathrm{D}_{\mathrm{w}, \mathrm{i}} \tau}}\right) \approx \mathrm{D}_{\mathrm{w}, \mathrm{i}}\left(\frac{1}{\mathrm{r}}+\sqrt{\frac{\mathrm{v}}{2 \pi \mathrm{r} \mathrm{D}_{\mathrm{w}, \mathrm{i}}}}\right)
$$

where $\tau$ is the contact time (i.e., the time a water parcel with flow velocity $v$ needs to pass by a bubble with diameter $2 r$ ).

The rate of change of dissolved mass for gas $i$ in each spherical air bubble can be expressed by

$$
\begin{aligned}
\frac{d n_{i}}{d t}=-A_{i n t} d_{i} & =-A_{i n t} k_{i}\left(c_{w, i}-\frac{p_{i}}{R T K_{H, i}}\right)= \\
- & 4 \pi r^{2} k_{i}\left(c_{w, i}-\frac{x_{i}}{S_{i}}\left(p_{a t m}-p_{w}+\rho g h+\frac{2 \sigma}{r}\right)\right)
\end{aligned}
$$

where $A_{\text {int }}$ is the surface area of the bubble, $x_{i}=n_{i} / n_{\text {tot }}$ is the mole fraction of gas $i$ in the bubble, $p_{a t m}$ is the barometric pressure, $p_{w}$ is the partial pressure of the water vapor in the bubble, $\rho$ gh is the hydrostatic pressure at depth $h, 2 \sigma r^{-1}$ is thecapillary pressureaccording to thecurvature of thebubble surface with surface tension $\sigma$, and $\mathrm{S}_{\mathrm{i}}=\mathrm{RTK}_{\mathrm{H}, \mathrm{i}}$ is the solubility of gas $i$. $n_{\text {tot }}=\sum_{i} n_{i}$ is the total number of moles of gas in the bubble. To describethedissolution of an entrapped air bubble and its effect on the dissolved noble gas concentrations, we assume the bubble to consist of the noble gases $\mathrm{He}, \mathrm{Ne}, \mathrm{Ar}$, $\mathrm{Kr}$, and Xeand the main air constituents nitrogen and oxygen. Index $i$ in eq 4 runs over all gases mentioned. The total gas exchange per unit time for one initial bubble size class is then given by the sum of the changes of all considered gases.

The change in bubble radius with time associated with this total mass transfer is described by

$$
\frac{\mathrm{dr}}{\mathrm{dt}}=\frac{3 \mathrm{RT}}{4 \pi \mathrm{r}}\left(\frac{1}{4 \sigma+3 r\left(\mathrm{p}_{\mathrm{atm}}-\mathrm{p}_{\mathrm{w}}+\rho \mathrm{gh}\right)}\right) \frac{\mathrm{dn_{ \text {tot } }}}{\mathrm{dt}}
$$

If different-sized bubbleclasses are postulated, thetemporal evolution of dissolved gas i referring to concentrations in water is

$$
\frac{\mathrm{dc}_{\mathrm{w}, \mathrm{i}}}{\mathrm{dt}}=\sum_{\mathrm{r}} \frac{\mathrm{n}_{\text {bubble, }} \mathrm{A}_{\text {int, } \mathrm{r}}}{\mathrm{v}_{\mathrm{w}}} \mathrm{j}_{\mathrm{i}, \mathrm{r}}=\sum_{\mathrm{r}} \frac{\mathrm{n}_{\text {bubble, } \mathrm{r}}}{\left(\frac{\mathrm{v}_{\text {tot }} \theta}{\left(1+\mathrm{r}_{\alpha-\mathrm{w}}\right)}\right)} \frac{\mathrm{dn}_{\mathrm{i}, \mathrm{r}}}{\mathrm{dt}}
$$

where $\mathrm{n}_{\text {bubble, }}$ is the number of bubbles in the respective bubble size class, $\mathrm{V}_{\text {tot }}$ is the total volume, $\mathrm{V}_{\mathrm{w}}$ is the waterfilled volume, $\theta$ is the porosity, and $r_{\alpha-w}$ is the volume ratio of entrapped air and water in the pore space. To enable the calculation of $n_{\text {bubble }}$ for each bubbleclass, its volume fraction of the total air-filled pore space has to be specified. The coupled differential eqs 4-6 are the governing model 
equationsfor the mass transfer between water and entrapped air bubbles.

To obtain the differential equations describing aqueous phasetransport of the dissolved gases, we combinethe mass conservation statement for a control volume with the wellknown advection-dispersion equation (25). The onedimensional vertical flow is given by

$$
\begin{aligned}
\frac{\partial\left(\theta_{w} C_{w, i}\right)}{\partial t}=\frac{\partial}{\partial z}\left(\theta_{w} D_{z} \frac{\partial c_{w, i}}{\partial z}-\right. & \left.\theta_{w} v C_{w, i}\right)+B \\
= & \frac{\partial}{\partial z}\left(\theta_{w} D_{z} \frac{\partial c_{w, i}}{\partial z}-q c_{w, i}\right)+B
\end{aligned}
$$

where $\theta_{\mathrm{w}}$ is the water-filled porosity, $\mathrm{D}_{z}$ is the hydrodynamic dispersion coefficient in flow direction $\left(\mathrm{L}^{2} \mathrm{~T}^{-1}\right), \mathrm{v}$ is the aqueous phase velocity $\left(\mathrm{LT}^{-1}\right)$, and q is the water flux $\left(\mathrm{LT}^{-1}\right)$. $B$ represents the source term that results from the mass transfer between water and entrapped air bubbles given in eq 6. Note that $\theta_{\mathrm{w}}$ is assumed to increase with dissolution of the gas bubbles.

Finally, eqs 4-7 completely describe the dissolved gas transport in the presence of entrapped gas bubbles in groundwater. These model equations are solved numerically with the method of lines employing a fully implicit finite difference code.

The initial composition of the gas phase is preset to atmospheric values. The initial dissolved concentrations are usually at solubility equilibrium for the given temperature, salinity, and barometric pressure, but they may as well be changed to model more specific situations. From the given bubblesizes, initial bubble radii profiles for different depths are calculated assuming pressure equilibrium between the surrounding water and the bubbles at depth $\mathrm{h}$ :

$$
r^{3}(h)=\frac{3 n_{\text {tot }} R T}{4 \pi\left(p_{a t m}-p_{w}+\rho g h+2 \sigma r(h)^{-1}\right)}
$$

In the final phase of the bubble dissolution when the bubble volume tends to zero and the capillary pressure evolves to infinity, the following rigorous scheme is utilized in the numerical simulation: If the number of moles of any conservative gas in the bubble reaches zero, the bubble is immediately forced to dissolve completely. This means that the remaining amounts of all other gases are transferred into the water, and the bubble radius at the end of the time step is set to zero. This procedure is based on the observation that, in a liquid, the smallest gas bubbles collapse under the influence of theenlarged capillary pressureand that the final bubble dissolution phase is irreversible. Numerically, variable time steps are used in the model. To resolve the final dissolution stage correctly, before the bubble extinction the time step size is progressively reduced to $1 \mathrm{~s}$.

\section{Results and Discussion}

The kinetic bubble dissolution (KBD) model describes an efficient method to assess the relevance of entrapped gas bubbles on the solute transport in porous media. While virtually any kind of entrapped gas can be considered in the model-provided its solubility and its molecular diffusivity in water is known-we will focus on entrapped air bubbles with atmospheric composition being present in the upper, quasi-saturated groundwater zone. To elucidate the capabilities of the model, we discuss in the following results a set of simulations employing various model parameters.

IllustrativeModel Application. For a moredetailed insight into the physical concepts of the KBD model, the results of a model simulation of a 1-m sand column are presented in Figure 1. The model parameters used in this simulation are given in Table 1 . In the simulation, a vertical spatial discretization of $1 \mathrm{~cm}$ was employed. Two different scenarios wereconsidered: an advectiveflow regimewith vertical water flow in the simulated substrate column and a stagnating situation without advective transport. Except for the flow velocity and the dispersion coefficient associated with the flow, themodel parameters areidentical in thetwo scenarios.

Stagnant Flow Regime. For the stagnant conditions, the entrapped air bubbles in the simulated 1-m aquifer column dissolveonly partially (Figure 1a). As a result of theincreased pressure acting on the bubbles, gas will be transferred into the water until a new equilibrium condition between the surrounding water and the remaining gas phase is reached. The relative change in bubble size as well as in dissolved gas concentrations increases with depth (i.e., with increasing hydrostatic pressure). Analogously, the time to reach equilibrium between the entrapped gas phase and the surrounding water increases with depth.

Figure 1 b shows relative concentrations of the noblegases ( $\mathrm{He}, \mathrm{Ne}, \mathrm{Ar}, \mathrm{Kr}, \mathrm{Xe}$ ) and of oxygen and nitrogen near the bottom of the modeled column at $0.95 \mathrm{~m}$ depth for stagnant conditions. The diffusivities of the gases in water and their solubilities are given in Table 2. Starting from solubility equilibrium (c: $\mathrm{c}_{\mathrm{ini}}=1$ ) at the given temperature, salinity, and pressure, the dissolved concentrations rise for all gases as a result of the mass transfer from the gas bubbles into the water. The final degree of concentration increase is entirely controlled by the solubility of the gases: Higher solubility gases result in a smaller relative rise in the water phase. Therefore the response of gases with a low solubility such as $\mathrm{He}$ and $\mathrm{Ne}$ is most sensitive to air injection and can indicate the presence of dissolved excess air. The resulting new dissolved gas composition equals the prediction of the excess air model describing bulk dissolved gas abundance patterns in groundwater as the result of closed-system equilibration between entrapped air and a stagnant water body (11). The KBD model allows us to study the transition from the initial condition toward the new equilibrium, which is influenced by the diffusivities of the gases in water. The time to reach thenew equilibrium concentration decreases with increasing diffusivity of the gas (Figure 1b). Since nitrogen and oxygen diffuse more slowly in water than Ar, their concentrations are rising slower than the Ar concentration. But as Ar is more soluble, the final degree of supersaturation islarger for oxygen and nitrogen than for Ar. In result, the oxygen and nitrogen concentration curves cross theAr concentration curve before reaching the final equilibrium state.

Generally, thetemporal scale of the equilibration between entrapped air and closed water phase depends on the initial bubble size distribution and on the air-water ratio in the porespace. An increasing amount of entrapped gas in relation to the water volume leads to a prolongation of the equilibration time. If the air-water ratio is considered constant, a distribution of the entrapped air volume in small bubbles facilitates the equilibration process and hence results in a shorter equilibration timeas compared to that based on larger bubbles.

If multiple entrapped bubble sizes are assumed, the bubblesizes are rearranged, leaving only one hydrostatically stable bubble class. As this redistribution takes place diffusively, the time scale of the overall dissolution process in themultiple-sizesimulation issignificantly prolonged. Details are given in the Supporting Information.

AdvectiveFlow Regime. If weassumea vertical downward water flow in the modeled substrate column, the entrapped air bubbles dissolve completely (Figure 1c). Because of the permanent supply of water that is undersaturated with respect to the local pressure at a considered depth, a continuous mass transfer from the entrapped gas bubbles into the water takes place. As a result, the entrapped air is finally completely dissolved. The time needed for the 

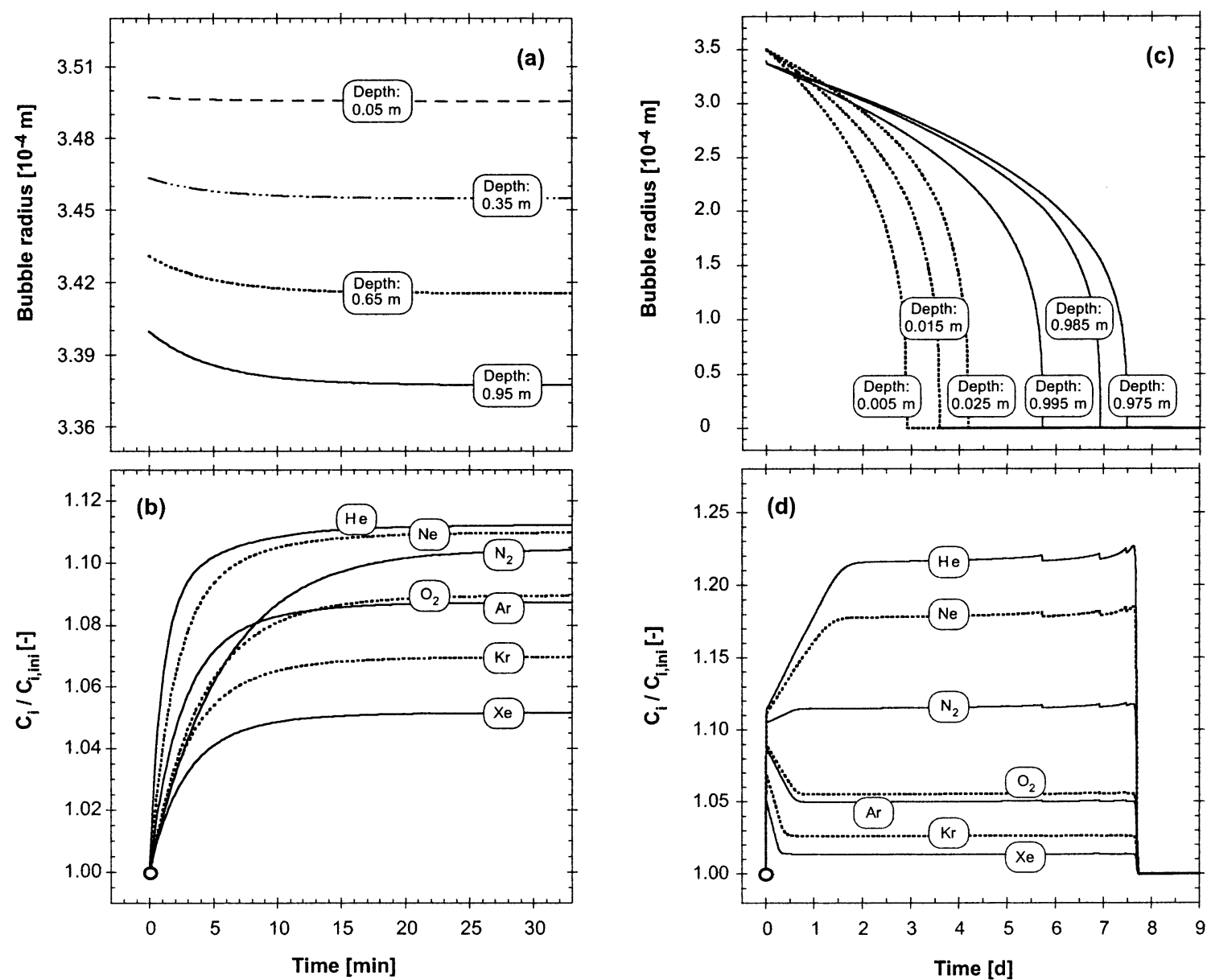

FIGURE 1. Bubble radii and relative concentrations of $\mathrm{He}, \mathrm{Ne}, \mathrm{Ar}, \mathrm{Kr}, \mathrm{Xe}, \mathrm{N}_{2}$, and $\mathrm{O}_{2}$ in the water phase from the KBD model simulation using the model parameters show $\mathrm{n}$ in Table $1 . C_{i, \text { ini }}$ is the initial water concentration of gas $i$. Panels a and $b$ show the results for stagnant, no-flow conditions. Panels $\mathrm{c}$ and $\mathrm{d}$ display the simulations for an advective vertical dow $\mathrm{nw}$ ard $\mathrm{w}$ ater flow in the modeled aquifer column. Panel $b$ shows results from near the bottom $(0.95 \mathrm{~m}$ depth) of the $1-\mathrm{m}$ column, and panel $\mathrm{d}$ show $\mathrm{s}$ results from the column outflow.

TABLE 1. Model Parameters Used in the KBD Model Simulations

\begin{tabular}{l}
\multicolumn{1}{c}{ model parameter } \\
\hline \multicolumn{1}{c}{ simulation } \\
column length $(\mathrm{m})$ \\
no. of bubble classes \\
initial bubble radius in class $(\mathrm{mm})$ \\
total porosity \\
air-water ratio \\
water temperature $\left({ }^{\circ} \mathrm{C}\right)$ \\
atmospheric pressure $(\mathrm{atm})$ \\
hydrostatic overburden $(\mathrm{atm})$ \\
salinity $(\%)$ \\
flow velocity vertical flow $(\mathrm{cm} / \mathrm{h})$ \\
flow velocity stagnant regime $(\mathrm{cm} / \mathrm{h})$ \\
initial water concentration
\end{tabular}

\begin{tabular}{ll}
\multicolumn{2}{c}{ value } \\
\hline standard & hydrostatic overburden \\
1 & 1 \\
1 & 1 \\
0.35 & 0.35 \\
0.4 & 0.4 \\
0.1 & 0.2 \\
20 & 8 \\
1 & 0.9615 \\
0 & 0.02 \\
0 & 0 \\
10 & 10 \\
0 & \\
$C_{\text {equi }}$ & $C_{\text {equi }}+8 \times 10^{-4} \mathrm{~cm}^{3}$ \\
& air/g of water
\end{tabular}

completeair bubble extinction is orders of magnitudes larger than thetimethat is required for establishing new equilibrium conditions in the stagnant regime ( $\sim 8 \mathrm{~d}$ vs $\sim 30 \mathrm{~min})$.

In Figure 1c, the bubble radii in theuppermost and in the lowermost three depth levelsare shown with time. Regarding thechronology of the bubblecollapses at the different depths, two competing mechanisms that influence the evolution of the bubbleextinction within the vertical column areevident. The hydrostatic pressure acting on the bubbles favors a bubble dissolution sequence from bottom to top (depth 0.995-0.975 m, Figure 1c) whereas the freshwater flushing of the column enhances the extinction from the top to the bottom of the column (depth $0.005-0.025 \mathrm{~m}$, Figure 1c). Depending on the flow velocity, the air-water ratio in the pore space, the column length, and the initial bubble sizes, any kind of spatial sequence of bubbledissolution is possible.

In Figure 1d, the relative dissolved gas concentrations in the outflow are shown for the vertical water flow regime. Compared to the time scale for the complete dissolution process, the first adaptation of the dissolved concentrations in response to the application of pressure on the entrapped air occurs very fast (within afew minutes). Theconcentrations riserapidly from solubility equilibrium to theinitial solubilitycontrolled supersaturation pattern that resembles the final 
TABLE 2. Molecular Diffusivities and Dimensionless Henry Coefficients

\begin{tabular}{|c|c|c|c|c|c|c|}
\hline & \multicolumn{3}{|c|}{$\begin{array}{c}D_{i}^{a} \\
\left(10^{-5} \mathrm{~cm}^{2} / \mathrm{s}\right)\end{array}$} & \multicolumn{3}{|c|}{$\begin{array}{c}K_{H, i}^{b} \\
{[(\mathrm{~mol} / \mathrm{L} \text { of gas }) /(\mathrm{mol} / \mathrm{L} \text { of water })]}\end{array}$} \\
\hline & $5^{\circ} \mathrm{C}$ & $15^{\circ} \mathrm{C}$ & $25^{\circ} \mathrm{C}$ & $5^{\circ} \mathrm{C}$ & $15^{\circ} \mathrm{C}$ & $25^{\circ} \mathrm{C}$ \\
\hline $\mathrm{He}$ & 5.10 & 6.30 & 7.22 & 107 & 107 & 105 \\
\hline $\mathrm{Ne}$ & 2.61 & 3.28 & 4.16 & 83.4 & 88.0 & 90.7 \\
\hline $\mathrm{Ar}$ & 1.63 & 2.13 & 2.69 & 20.9 & 25.2 & 29.3 \\
\hline $\mathrm{Kr}$ & 1.02 & 1.41 & 1.84 & 10.5 & 13.4 & 16.4 \\
\hline $\mathrm{Xe}$ & 0.774 & 1.12 & 1.47 & 5.36 & 7.29 & 9.41 \\
\hline $\mathrm{N}_{2}$ & 1.11 & 1.49 & 1.96 & 46.8 & 55.6 & 63.5 \\
\hline $\mathrm{O}_{2}$ & 1.36 & 1.80 & 2.35 & 22.9 & 27.7 & 32.2 \\
\hline
\end{tabular}

a Molecular diffusivites in water. Measured values for $\mathrm{He}, \mathrm{Ne}, \mathrm{Kr}$, and Xe were taken from ref 26. The diffusivity of Ar was approximated by the relationship $D_{i} \sim$ mass $_{i}^{-0.5}$ using the measured values of $\mathrm{He}, \mathrm{Ne}$, $\mathrm{Kr}$, and Xe. Diffusivities of oxygen and nitrogen were taken from ref 27. ${ }^{b}$ Dimensionless Henry coefficients. They are calculated using the equilibrium concentrations from refs $28-30$ for $\mathrm{He}, \mathrm{Ne}, \mathrm{Ar}, \mathrm{Kr}, \mathrm{O}_{2}$, and $\mathrm{N}_{2}$ and from ref 31 for $\mathrm{Xe}$.

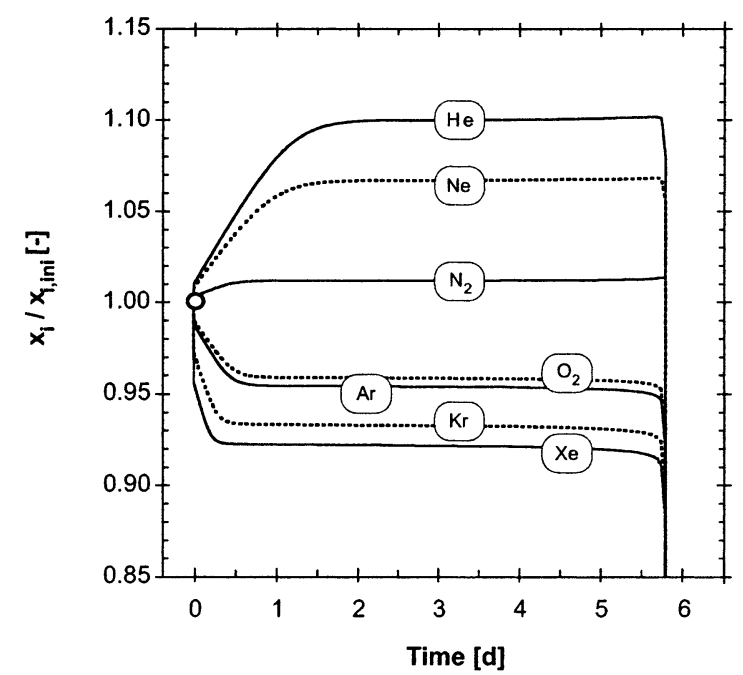

FIGURE 2. Relative gas composition of the dissolving gas phase for the vertical advective $w$ ater flow regime in the low ermost depth class. $x_{i, i n i}$ is the initial concentration of gas $i$ in the gas bubbles.

state of the stagnant simulation. Afterward, the relative concentrations of the different gases evolve in different ways. The concentrations of the gases of low solubility increase whereas those of the heavier gases with a high solubility decrease. This is explained by the solubility-controlled changes in the relative gas composition of theentrapped gas phase (Figure 2). The total gas pressure in the bubbles is dominated by nitrogen, which has the highest abundance of all considered gases. As a result, the relative contribution of nitrogen to the gas composition remains nearly constant throughout the wholebubble dissolution process. I n contrast and as a direct result of the enhanced mass transfer into the water, the mole fractions of the highly soluble gases such as $\mathrm{Kr}$ or Xe decrease in the gas phase, which in turn causes a relativedecreasein the dissolved concentration of thesegases. Because of the the low solubility of the light noble gases, their mole fraction in the gas phase is enlarged during the bubble dissolution process, resulting in the equivalent increase in the dissolved concentrations as shown in Figure $1 d$. After these concentration changes, a plateau-like phase with a nearly constant concentration pattern is reached that resembles a quasi-steady-state condition, although the dissolution process is still continuing. This quasi-steadystate is again reached the faster, the more soluble the gas is. After the entrapped gas volume is completely removed, the concentrations in the column outflow decrease toward the prescribed solubility equilibrium concentrationsfor all gases.

With the extinction of the entrapped air bubbles in the lower-most column box, a small peak is manifest in the dissolved concentrations of all gases (Figure ld). This increase reveals the transfer of the remaining gas volume into the water volume at the depth associated with the bubble collapse. Because the light gases with low solubility react most sensitively to air transfer, they show the most pronounced peak. The bubble dissolution in the adjacent upstream column boxes also influences the outflow concentrations and generates the second and the third peaks, respectively.

The decisive quantity that controls the temporal scale of the extinction of entrapped air bubbles is the amount of gas-relative to the total entrapped air volume-that can be dissolved per time step in a given water volume. A decrease of the flow velocity $(v)$ and an increase in the air-water ratio $\left(r_{\alpha-w}\right)$ both prolong the time needed for a complete bubble dissolution, as the amount of entrapped air soluble per time step is reduced. Viceversa, if $v$ is increased, the rapid flushing of the column leads to a faster dissolution of the entrapped gas phase. Similarly, a decrease in $r_{\alpha-w}$ leads to a distribution of the dissolved gas on a larger water volume and, hence, a more effective gas dissolution process and a faster bubble extinction.

The distribution of the entrapped gas volume into different-sized bubble classes only slightly affects the dissolution process. In contrast to the stagnant flow regime, the vertical water transport dominates the bubble dissolution processes, which minimizes the effect of the bubble size rearrangement taking place. More details are given in the Supporting Information.

Comparison of Model Resultsand Measured Data. Noble gas data from actual column experiments are in general agreement with theillustrative calculations presented above as has been demonstrated by ref 32 . Here we present results from a large-scale column experiment using a sand filter in the waterworks of the city of Zurich, Switzerland, which were used to test the applicability of the KBD model.

The $1 \mathrm{~m} \times 1120 \mathrm{~m}^{2}$ filter of initially dry quartz sand was water-saturated from the bottom of the sand to the top. During this process, air bubbles are entrapped in the sand. In the next step, the water level in the system was raised 20 $\mathrm{cm}$ above the sand surface, and a vertical downward water flow through the sand filter was initiated. Because of the constant water supply to and discharge from the sand filter, the hydraulic conditions in the system can be considered constant. The water at the inflow and at the outlet of the filter was sampled for noble gas analysis. Details on sampling procedure and analytical method are given in ref 33.

The water in the inflow is not in solubility equilibrium with theatmosphere, but it containsal ready an approximately constant dissolved gas excess with atmospheric composition. This initial supersaturation is the result of the pretreatment of the water in the waterworks. In the operation mode, the air that is entrapped in the first imbibition process is continuously dissolved, resulting in a dissolved gas excess that exceeds the input concentrations and that is detectable at the outflow of the filter very soon after the start. The parameters of the model simulation considering one bubble class are given in Table 1 (hydrostatic overburden). Except for the initial bubble size and the air-water ratio, all parameters are known from the experiment. The two free parameters were adjusted such that the model results agree well with the first six measurements of He. Using these parameters, the model was employed to predict $\mathrm{He}$ and $\mathrm{Ne}$ concentrations. The model results and the measured Heand Ne data agree very well (Figure 3). The KBD model correctly predicts the initial concentration rise, the following plateaulikephase, and the final collapse of theentrapped air bubbles. 

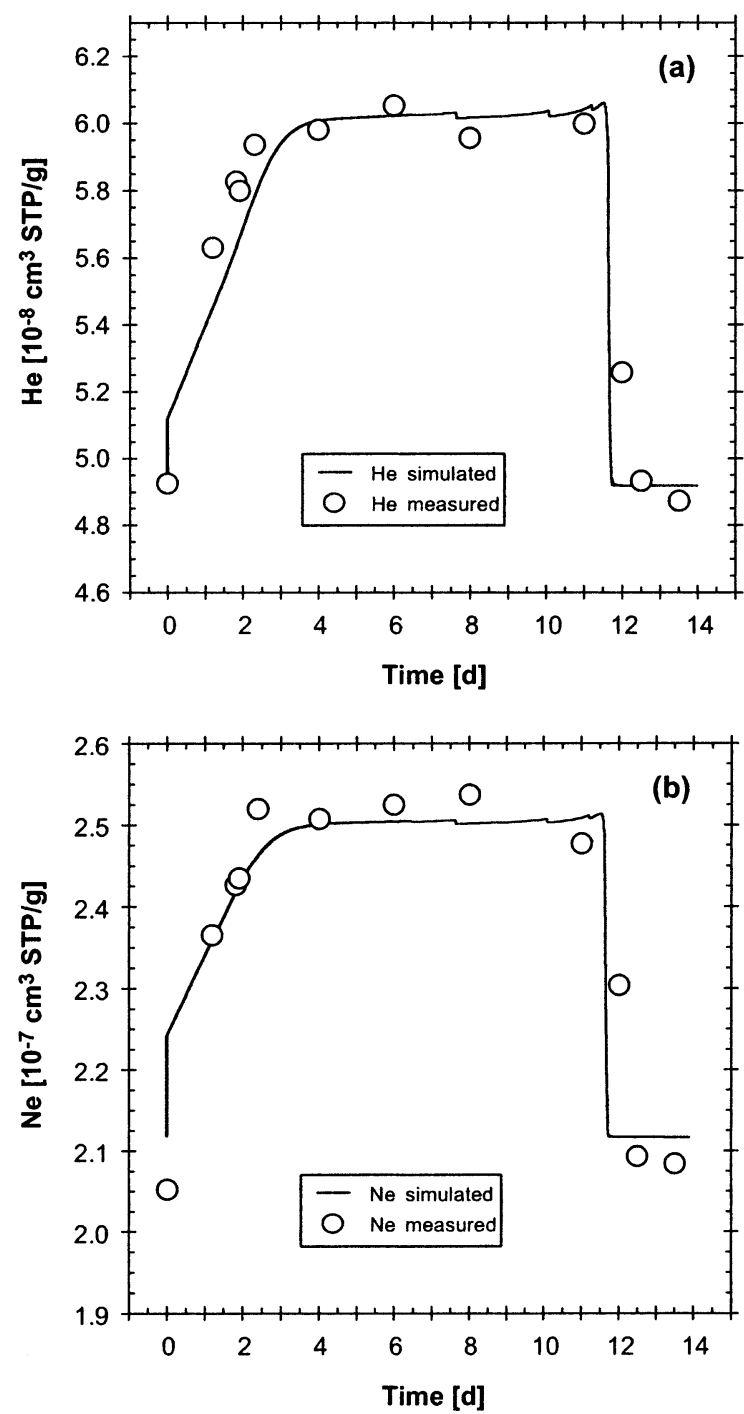

FIGURE 3. Comparison between measured $\mathrm{He}$ and $\mathrm{Ne}$ data and simulation results. The experiment investigated the formation of excess air in a quartz sand filter in the waterw orks of the city of Zurich, Sw itzerland. The simulation parameters are given in Table 1 (hydrostatic overburden). Initial and upper boundary concentrations are $\mathrm{He}=4.92 \times 10^{-8} \mathrm{~cm}^{3} \mathrm{STP} / \mathrm{g}$ and $\mathrm{Ne}=2.12 \times 10^{-7} \mathrm{~cm}^{3} \mathrm{STP} / \mathrm{g}$.

The very good agreement between the overall concentration profile predicted by the KBD model and the measured data supports the validity of the model and the conceptualizations made within the model. The KBD model also predicts the concentrations of the heavier noble gases $\mathrm{Ar}, \mathrm{Kr}$, and $\mathrm{Xe}$ reasonably well. Because of their larger solubility, they are much less sensitive to dissolution of entrapped air than the light noble gases $\mathrm{He}$ and $\mathrm{Ne}$, resulting in less significant excesses that are not shown here. Acomprehensivediscussion of the complete data set from the Zurich waterworks experiment will be presented elsewhere.

Relevance of Subsurface Bubble-Mediated Oxygen Transfer. Entrapped air bubbles in the upper, quasi-saturated groundwater zone are a relevant source of dissolved gases in groundwater. The dissolution of entrapped air serves in particular as an important oxygen supply for the aquatic fauna in the transition zone between groundwater and soil air. As per volume, 28 times more oxygen is contained in entrapped air than is dissolved in water at atmospheric solubility equilibrium at $15{ }^{\circ} \mathrm{C}$ (20). Entrapped air will significantly enhance all biogeochemical processes within thequasi-saturated zone for which oxygen is the rate-limiting
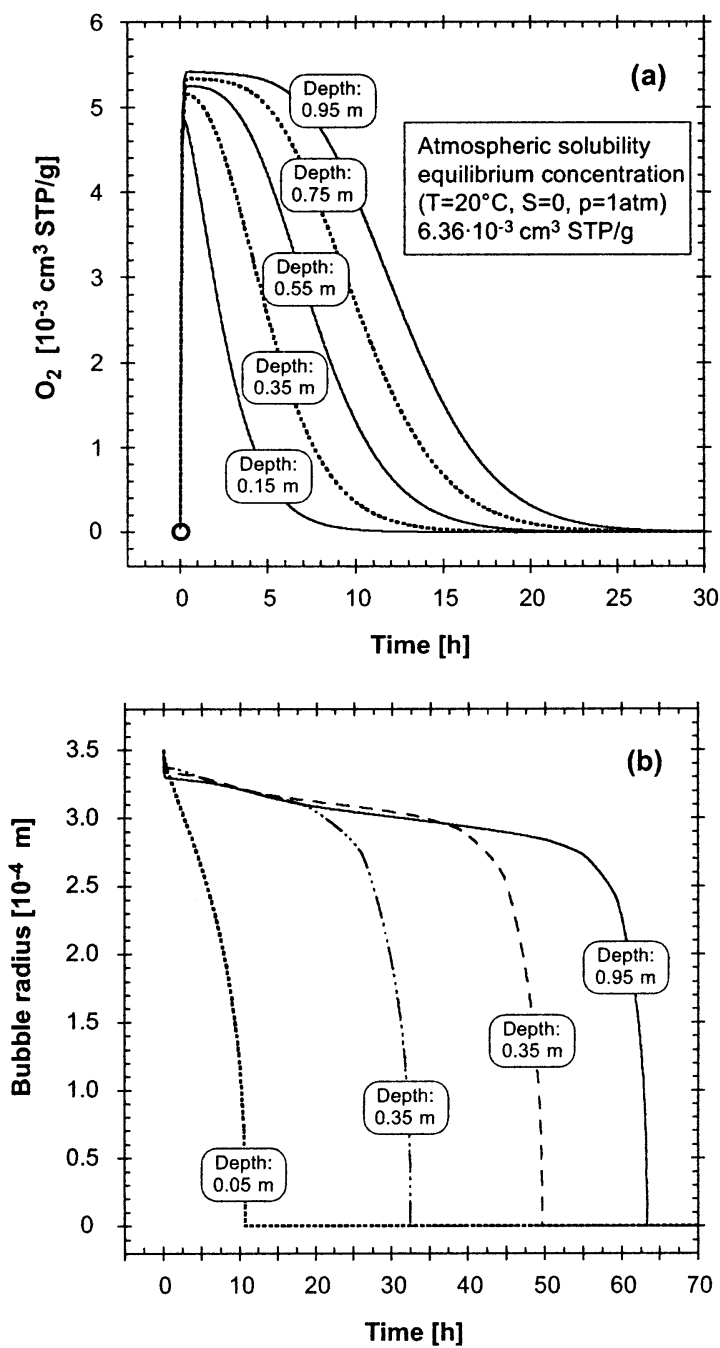

FIGURE 4. Oxygen concentrations and bubble radii from the KBD model simulation considering anoxic water flowing through the simulated aquifer column. The different lines correspond to the results at different depths of the column.

factor. Especially in aquifers with cyclic groundwater level fluctuations that steadily refill the entrapped air volume, the bubble-mediated oxygen supply will work most efficiently. Considering anoxic groundwaters, the importance of the bubble-mediated oxygen supply is even larger. Examples for the occurrence of anoxic groundwaters are the downstream zone of in-situ redox manipulations (19) of contaminated aquifers and aquifer systems that are charged by carbonrich wastewater inflows (34).

To demonstrate the importance of entrapped air for the oxygen supply in anoxic environments, we simulated a 1-m aquifer column with entrapped air that is flown through by oxygen-free water (see model parameters in Table 1). As a result of the entrapped air bubble dissolution, the dissolved oxygen concentrations rise nearly immediately to a noticeable level (Figure $4 \mathrm{a}$ ). Because of the bubble extinction from top to bottom of the column, the oxygen concentration in the outflow shows significant oxygen values for a relatively long time. The temporary oxygen input from the upper parts of the column retards the completion of the bubble extinction in the lower column parts (Figure 4b). The overall oxygen input from the entrapped air bubbles for this simulation is about $4750 \mathrm{~cm}^{3}$ or $3.4 \mathrm{~g}$ of dissolved oxygen in $24 \mathrm{~h}$. To attain this amount of dissolved oxygen solely by diffusion across thegroundwater table would takeseveral months. Thisclearly points out the ecological importance of the bubble-mediated gas exchange in the upper, quasi-saturated aquifer zone. 
This example emphasizes the importance of entrapped air bubble dissolution for the dissolved gas budget in groundwater. The presented KBD model helpsin quantifying this type of bubble-mediated gas transfer in porous media and promises new interesting applications in the field of environmental sciences.

\section{Supporting Information Available}

Additional details including one figure. This material is availablefree of chargevia the Internet athttp:// pubs.acs.org.

\section{Literature Cited}

(1) Leonard, J. H.; Houghton, G. Chem. Eng. Sci. 1963, 18, 133.

(2) Lochiel, A. C.; Calderbank, P. H. Chem. Eng. Sci. 1964, 19, 471.

(3) Takemura, F.; Yabe, A. Chem. Eng. Sci. 1998, 53, 2691.

(4) Broecker, H. C.; Siems, W. In Gas Transfer at Water Surfaces; Brutsaert, W., Jirka, G. H., Eds.; D. Reidel Publishing Company: Dordrecht, The Netherlands, 1984; pp 229-236.

(5) Memery, L.; Merlivat, L. Tellus 1985, 37B, 272.

(6) Wüest, A.; Brooks, N. H.; Imboden, D. M. Water Resour. Res. 1992, 28, 3235

(7) Heaton, T. H. E.; Vogel, J. C. J. Hydrol. 1981, 50, 201.

(8) Kipfer, R.; Aeschbach-Hertig, W.; Peeters, F.; Stute, M. In Noble Gases in Geochemistry and Cosmochemistry; Porcelli, D., Ballentine, C., Wieler, R., Eds.; Reviews in Mineralogy and Geochemistry 47; Mineralogical Society of America: Washington, DC, 2002; pp 614-699.

(9) Stute, M.; Forster, M.; Frischkorn, H.; Serejo, A.; Clark, J. F.; Schlosser, P.; Broecker, W. S.; Bonani, G. Science 1995, 269, 379.

(10) Beyerle, U.; Aeschbach-Hertig, W.; Hofer, M.; Imboden, D. M.; Baur, H.; Kipfer, R. J. Hydrol. 1999, 220, 169.

(11) Aeschbach-Hertig, W.; Peeters, F.; Beyerle, U.; Kipfer, R. Nature 2000, 405, 1040

(12) Peeters, F.; Beyerle, U.; Aeschbach-Hertig, W.; Holocher, J.; Brennwald, M. S.; Kipfer, R. Geochim. Cosmochim. Acta 2002, 67, 587.

(13) Schlosser, P.; Stute, M.; Dörr, C.; Sonntag, C.; Münnich, K. O. Earth Planet. Sci. Lett. 1988, 89, 353.

(14) Holocher, J.; Matta, V.; Aeschbach-Hertig, W.; Beyerle, U.; Hofer, M.; Peeters, F.; Kipfer, R. Ground Water 2001, 39, 841.
(15) Busenberg, E.; Plummer, N. L. Water Resour. Res. 2000, 36, 3011.

(16) Gupta, S. K.; Lau, L. S.; Moravcik, P. S. Ground Water 1994, 32, 96.

(17) Fry, V. A.; Istok, J. D.; Semrini, L.; O’Reilly, K. T.; Buschek, T. Ground Water 1995, 33, 391.

(18) Donaldson, J. H.; Istok, J. D.; Humphrey, M. D.; O'Reilly, K. T.; Hawelka, C. A.; Mohr, D. H. Ground Water 1997, 35, 270.

(19) Williams, M. D.; Oostrom, M. J. Hydrol. 2000, 230, 70.

(20) Fry, V. A.; Selker, J. S.; Gorelick, S. M. Water Resour. Res. 1997, 33, 2687.

(21) Clift, R.; Grace, J. R.; Weber, M. E. Bubbles, Drops and Particles; Academic Press Inc.: New York, 1978.

(22) Cussler, E. L. Diffusion-Mass Transfer in Fluid Systems, 2nd ed.; Cambridge University Press: Cambridge, 1997.

(23) Schwarzenbach, R. P.; Gschwend, P. M.; Imboden, D. M. Environmental Organic Chemistry, 2nd ed.; John Wiley \& Sons Inc.: New York, 2002.

(24) Epstein, P. S.; Plesset, M. S. J. Chem. Phys. 1950, 18, 1505.

(25) Bear, J. Dynamics of Fluids in Porous Media; Dover Publications Inc.: New York, 1972

(26) Jähne, B.; Heinz, G.; Dietrich, W. J. Geophys. Res. 1987, 92, 10767.

(27) Broecker, W. S.; Peng, T.-H. Tellus 1974, 26, 21.

(28) Weiss, R. F. Deep-Sea Res. 1970, 17, 721.

(29) Weiss, R. F. J. Chem. Eng. Data 1971, 16, 235.

(30) Weiss, R. F.; Kyser, T. K. J. Chem. Eng. Data 1978, 23, 69.

(31) Clever, H. L., Ed. Krypton, Xenon and Radon-Gas Solubilities; Pergamon Press: Oxford, 1979; Vol. 2.

(32) Holocher, J.; Peeters, F.; Aeschbach-Hertig, W.; Hofer, M.; Brennwald, M.; Kinzelbach, W.; Kipfer, R. Geochim. Cosmochim. Acta 2002, 66, 4103.

(33) Beyerle, U.; Aeschbach-Hertig, W.; Imboden, D. M.; Baur, H.; Graf, T.; Kipfer, R. Environ. Sci. Technol. 2000, 34, 2042.

(34) Ronen, D.; Magaritz, M.; Almon, E.; Amiel, A. J. Water Resour. Res. 1987, 23, 1554.

Received for review April 11, 2002. Revised manuscript re ceived January 16, 2003. Accepted January 24, 2003.

ES025712Z 